\title{
Voltage-Source Control of DFIG in Standalone Wind Power-Based Microgrids
}

\author{
Hai Xiao, *Zhuoli Zhao, Member, IEEE, Keyu Zhou, Juntao Guo, Chun Sing Lai, Senior Member, \\ IEEE, Loi Lei Lai, Fellow, IEEE
}

\begin{abstract}
As the penetration of wind power increases, there is a growing operational demand on Wind Turbine (WT) systems to participate in microgrids frequency regulation. Traditional grid-connected Doubly-Fed Induction Generator (DFIG) control strategies are basically dependent on the power grid which is strong enough through the phase-locked loop (PLL). Traditional control strategies are not applicable to the weak grid with a relatively large short-circuit ratio (SCR). A new method must be introduced to let the wind farm actively respond to system frequency changes. This paper presents a control strategy which enables DFIG to behave as a voltage source. The droop curve is designed to realize the power sharing between DFIGs and battery energy storage system (BESS). Also, the grid frequency and phase angle required for coordinated transformation are no longer obtained through the phase-locked loop, but generated through the droop controller. Simulation results under various operation conditions are presented to verify the effectiveness of the proposed control strategy.
\end{abstract}

Index Terms--Doubly-Fed Induction Generator (DFIG), frequency regulation, microgrids, weak grid, voltage source operation

\section{INTRODUCTION}

$\mathrm{D}_{\mathrm{b}}^{\mathrm{L}}$ URING the past decades, more and more attention has been paid to energy issues. Wind energy is an important part of distributed generations (DG) system, and its development and utilization has always been a research focus of distributed power generation system. Doubly-Fed Induction Generator (DFIG) has been widely used in the wind generation systems due to its wide range of speed regulation. The classical problems of wind generation have already been solved widely. In [1], a direct voltage controlbased synchronization method is introduced to make sure that less more transient effect during synchronization of DFIG to the grid. Field-orient control (FOC) is the most popular controller which is used to control DFIG in normal operation. The main advantages are the simplicity, reliability and the decoupling of the dynamics of the DFIG allowing to regulate active and reactive power independently [2]-[4]. Because of its poor performance of controlling DFIG when grid disturbances occur, many improvement measures have been adopted to improve its stability [5]-[7].

However, new and severe challenges emerge when the

H. Xiao, Z. Zhao, K. Zhou, J. Guo and L. L. Lai are with the Department of Electrical Engineering, School of Automation, Guangdong University of Technology, Guangzhou, 510006, China (e-mail: 1033162832@qq.com; zhuoli.zhao@gdut.edu.cn; 544131332@qq.com; jt_guo22@163.com; 1.1.1ai@ieee.org).

C. S. Lai is with Brunel Institute of Power Systems, Department of Electronic \& Computer Engineering, Brunel University London, London, UB8 3PH, UK and also with the Department of Electrical Engineering, School of Automation, Guangdong University of Technology, Guangzhou, 510006, China (e-mail: chunsing.lai@brunel.ac.uk). wind power has high penetration. Most wind farms are located far away from the strong public power grid, because of the wind energy resource and the load center are distributed in reverse, which leads to the weak grid integration of large-scale wind turbines (WTs). Such high penetration of wind power integrated into weak grid, especially in some remote areas with a relatively large shortcircuit ratio (SCR), has presented multiple challenges of the security and stability of power system due to the randomness of wind power. To improve the system dynamic behavior of DFIG, the virtual inertial control was introduced in [8]-[12]. But this control method focuses on short-term oscillations and incorporates no long-term frequency regulation. Although the virtual inertia method has its advantages, it has been criticized because of its limited influence on the primary frequency adjustment. This limited contribution to transient performance is the main reason why many researchers try to find another way to make wind turbines participate in steady-state frequency regulation. Different problems related to frequency regulation of WTs system have been studied in recent years. The de-loaded control methods presented in [13] can respond to the system frequency regulation in real time by cut down the generator's usual efficiency to obtain reserved active power capability. The method of releasing the rotor kinetic energy by adjusting the rotor speed through changing the tracking curve of prime motor is discussed in [14]. Actually, most of the DFIG-based DGs are controlled in grid-feeding mode as current source in microgrids.

Therefore, there is a growing operational demand on DFIG systems to participate in microgrid regulation of frequency and voltage amplitude with voltage source output characteristic. Many researchers have studied control strategies of DFIG working in standalone mode. Authors in [15], present a new speed-sensorless control strategy for a standalone DFIG feeding an isolated load. In [16], stator flux-oriented vector control strategy is presented to supply an unbalanced grid/standalone load. The rotor side converter (RSC) can be used to control the stator voltage and frequency while the load side converter (LSC) is used to control the DC-bus voltage. In [17]-[18], a direct voltage control of stand-alone DFIG under asymmetric loads and non-linear loads is presented. All the control strategies above working in standalone mode do not allow DFIG participate in frequency regulation in microgrids. A comprehensive modeling, analysis, and stabilization of photovoltaic-based multiple microgrid clusters has been discussed in [19]. So far, no research work has been done to analyze the dynamic characteristics and enhance the stability of standalone microgrids considering the dynamics of interconnecting DFIG-based WTs. 
Motivated by the aforementioned research gap, this paper presents a modeling and analysis work of DFIG-based multiple microgrids. As there is no strong grid to rely on, the standalone DFIGs should work as voltage source, providing a constant voltage amplitude and frequency output to the microgrids. The voltage source output characteristic is established by applying an indirect stator flux orientation strategy on the RSC to control voltage output amplitude by adjusting the excitation current. The purpose of LSC is the same as grid-connected DFIG to maintain the stability of the DC link voltage, so the traditional control strategy is also applicable in this method. Droop control is suggested by many researchers to solve the problem of power distribution. In [20], detailed analysis of droop control in microgrids has been reported. A microgrid system consisting of two DFIGs and one BESS was established in MATLAB/Simulink to verify the proposed control strategies.

The rest of the paper is organized as follows. Section II presents the system architecture of the DFIG-based microgrids. Section III introduces the proposed voltagesource droop control strategy of DFIG in standalone microgrids. The simulation results and detailed analysis are presented in Section IV. Conclusions are drawn in Section V.

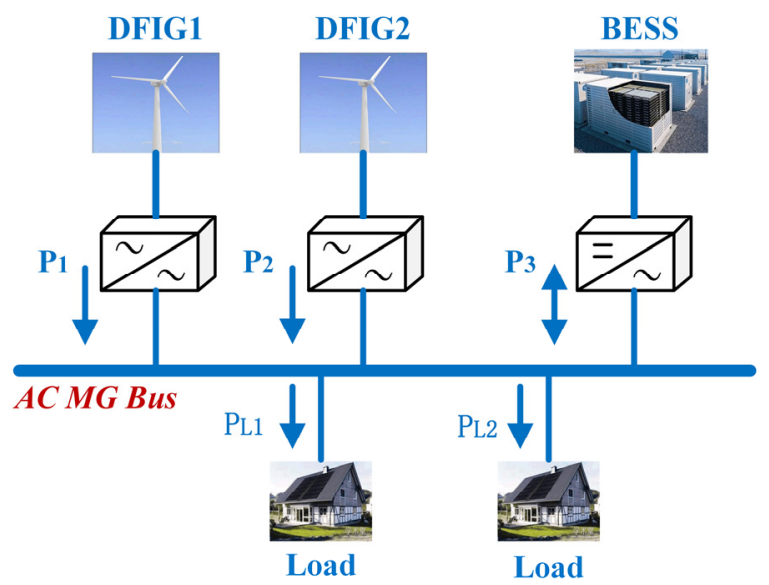

Fig. 1 System structure of standalone microgrid.

\section{SySTEM ARCHITECTURE OF DFIG-BASED STANDALONE MICROGRIDS}

Standalone microgrid has gradually become a hot research point. A typical islanded medium-voltage (MV) microgrid placed in Dongao Island is presented in [21]. To study the dynamics of DFIG-based standalone microgrid, a model was established in MATLAB/Simulink. The system structure is shown in Fig. 1. In order to achieve the operation requirements of the output characteristics of the voltage source at the end of the DFIG stator, the ISFO control strategy is adopted in the RSC. The phase angle required for flux linkage is calculated by the ISFO control strategy, which can be calculated in real time by detecting the motor's stator voltage, stator current, rotor speed and other easily measurable parameters. The integral part of the flux calculation can effectively avoid the instantaneous disturbance of the voltage at the load terminal side, keeping the output voltage relatively stable during the transient process. This control method has strong adaptability.

As shown in Fig.1, in this paper, isolated microgrids model including two DFIGs and one BESS is established to study the operation of different situation. For DFIG, a voltage source control strategy is adopted in the rotor side of DFIG to achieve voltage source output. The control system is composed of 1) droop control loop, which is used for setting the reference value of active and reactive power and outputting the reference value of frequency and voltage amplitude; 2)Flux calculation loop, generate the excitation current required to control the voltage amplitude and frequency; and 3) inner current control loop, which is used to let the current feedback value quickly track the reference value and generate a voltage signal that can be used for PWM control. For BESS, the control system contains three parts: 1) droop control loop, the purpose of it is the same as the droop control of DFIG; 2) Power control loop to control close dynamic characteristics of the output power; and 3) inner current control loop, which has the responsibility to control the current of the filter inductor and limit the inverter fault current.

\section{Proposed Voltage-Source Control Strategy of DFIG IN MICROGRIDS}

\section{A. Voltage Source Control of DFIG}

Areas with a high proportion of renewable energy installed capacity are facing many problems, such as frequency stability threatening grid security, insufficient dynamic reactive power support, and increasing difficulty in voltage control. Traditional wind turbine control strategies realize energy conversion through phase-locked loop control. When the voltage support of the AC system is weak and the short-circuit ratio is in insufficient, phase-locked synchronization cannot be achieved, and synchronization may even be unstable and offline. Renewable energy replaces conventional power supply installations, and the system frequency adjustment ability is significantly reduced, which requires wind turbines to have the same frequency adjustment ability as traditional thermal power generators. Voltage source control strategies of DFIG was adopted to solve these problems above.

In synchronously rotating reference frame, the voltage equation is given by:

$$
\left\{\begin{array}{l}
u_{d s}=R_{s} i_{d s}+\frac{d \psi_{d s}}{d t}-\omega_{s} \psi_{q s} \\
u_{q s}=R_{s} i_{q s}+\frac{d \psi_{q s}}{d t}+\omega_{s} \psi_{d s} \\
u_{d r}=R_{r} i_{d r}+\frac{d \psi_{d r}}{d t}-\left(\omega_{s}-\omega_{r}\right) \psi_{q r} \\
u_{q r}=R_{r} i_{d r}+\frac{d \psi_{q r}}{d t}+\left(\omega_{s}-\omega_{r}\right) \psi_{q s}
\end{array}\right.
$$

where $u_{d s}, u_{q s}, u_{d r}, u_{q r}$ are stator-side and rotor-side $d-q$ axes voltage, $R_{s}, R_{r}$ are stator and rotor resistance, $i_{d s}, i_{q s}, i_{d r}, i_{q r}$ are stator-side and rotor-side $d-q$ axes current, $\omega_{s}, \omega_{r}$ are stator and rotor frequency, the slip angle is expressed as $\omega_{s}-\omega_{r}, \psi_{d s}, \psi_{q s}, \psi_{d r}, \psi_{q r}$ are the statorside flux and rotor-side flux. 


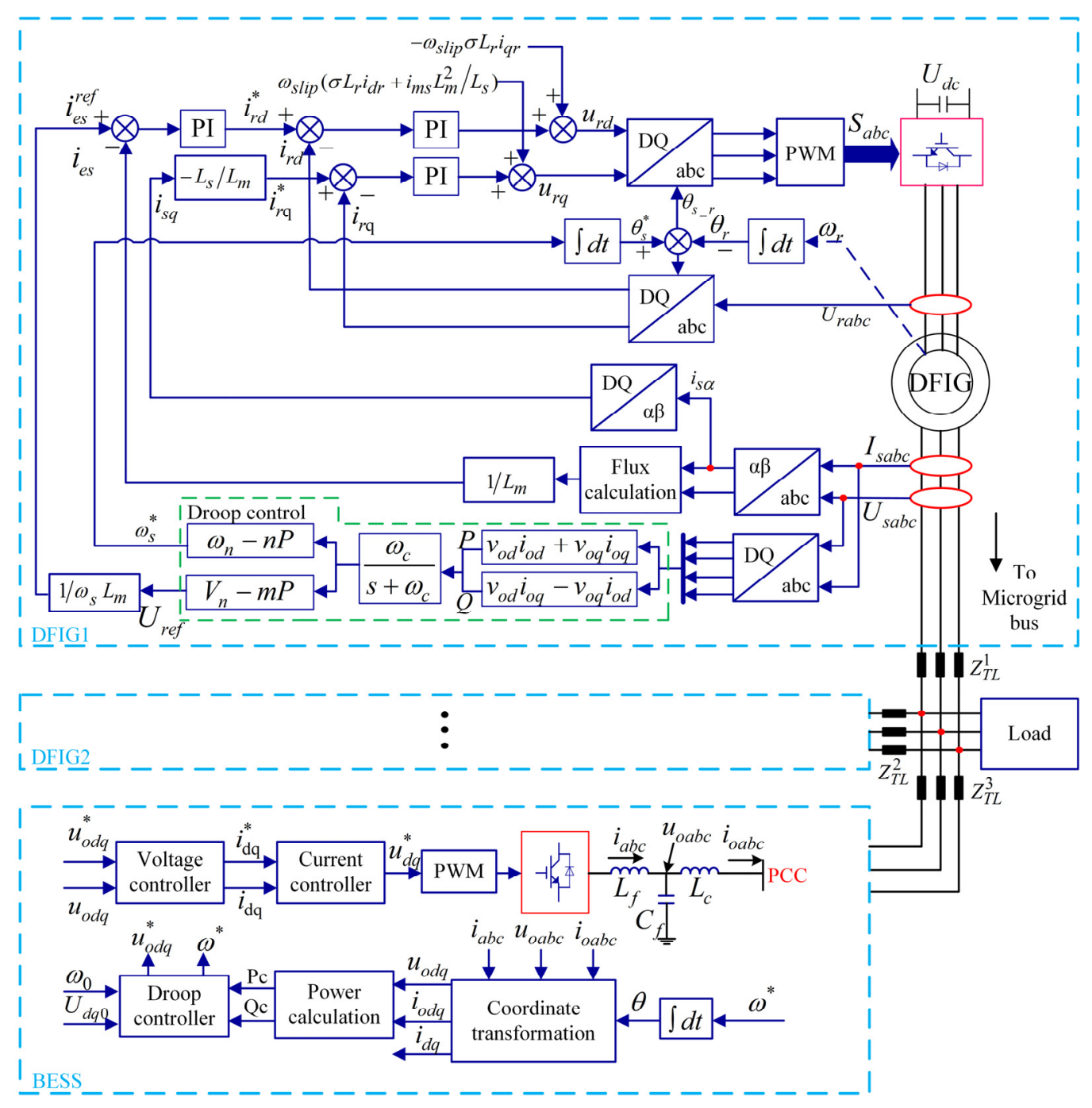

Fig. 2. Control structure of microgrid

The stator flux d-axis orientation is adopted in the DFIG control strategy, the stator and rotor flux equations can be expressed as:

$$
\left\{\begin{array}{l}
\psi_{d s}=L_{s} i_{d s}+L_{m} i_{d r} \\
\psi_{q s}=L_{s} i_{q s}+L_{m} i_{q r} \\
\psi_{d r}=L_{r} i_{d r}+L_{m} i_{d s} \\
\psi_{q r}=L_{r} i_{q r}+L_{m} i_{q s}
\end{array}\right.
$$

where mutual inductance is $L_{m}, L_{s}$ and $L_{r}$ are stator and rotor inductance. To achieve the control target of the amplitude of the stator voltage, set the reference value of the equivalent excitation current $i_{e s}^{r e f}$ which ignores the influence of the stator resistance.

$$
i_{e s}^{r e f}=\frac{U_{r e f}}{\omega_{s} L_{m}}
$$

where $U_{\text {ref }}$ represents the three-phase line voltage of DFIG stator. In this way, we can adjust the excitation current through PI controller so that it can track the reference value and keep the output voltage stable.

The control system of DFIG standalone mode is shown in Fig. 2. As shown in Fig. 2, PI controllers are used to regulate rotor currents. While load side control is the same as common grid-connected control strategies of DFIG to keep the DC link voltage stable. In order to simplify modeling and facilitate analysis, replace the DC capacitor with a DC voltage source. This will greatly improve the efficiency of the simulation.

\section{B. Dynamic Droop Control of DFIG}

In order to ensure the reliability and solve delay problems of long-distance transmission of real-time control signals, droop control is mostly used in current distributed generation systems to achieve power sharing. As shown in Fig. 2, a droop controller has been introduced to make DFIG take part in the regulation of voltage amplitude and frequency of microgrids. Each DG only depends on the electrical signals of the public connection point of the power generation system. It can realize the reasonable load distribution among different power generation units, which is simple, reliable and easy to realize.

\section{Microgrid Control Architecture}

The random characteristics of wind farm output have a greater impact on frequency adjustment of system. It is difficult to dampen system frequency changes only by relying on the support of DFIG-based wind farms. The 
frequency response of wind farms under high permeability conditions brings application prospects for BESS with fast power response capabilities. To realize the objective of maintaining the system frequency within the allowed range, a certain capacity of energy storage needs to be equipped with to stabilize the uncertainty of wind turbine output. Fig. 2 shows the block diagram of an inverter connected to the microgrid. In microgrid standalone mode, BESS unit usually works as a grid supporting voltage source, which can realize the active and reactive power sharing with other DGs.

As we all know, the wind speed has a decisive influence on the output energy power of wind turbines. We can dynamically adjust the output power energy of the wind turbines by adjusting the pitch angle. The influence of regulating pitch angle will be studied in the future work. Considering the DFIG operating in a constant speed when wind energy is enough, the main purpose of droop control is to provide flexible frequency and voltage support for the microgrids when working in the standalone mode.

The mathematical expression of power calculation is as follows:

$$
\left\{\begin{array}{l}
P=\frac{\omega_{c}}{s+\omega_{c}}\left(v_{o d} i_{o d}+v_{o q} i_{o q}\right) \\
Q=\frac{\omega_{c}}{s+\omega_{c}}\left(v_{o d} i_{o q}-v_{o q} i_{o d}\right)
\end{array}\right.
$$

$P$ and $Q$ are the real active power and the reactive power obtained by the instantaneous power components which are generated through low-pass filters. As shown in (4), $\omega_{c}$ represents the cut-off frequency of low-pass filters.

The mathematical expression of droop curve is expressed as:

$$
\left\{\begin{array}{l}
\omega_{i}=\omega_{0}-\frac{\omega_{0} * F_{\text {droopi }}}{P_{\max i}} P_{i} \\
u_{i}=u_{0}-\frac{u_{0} * Q_{\text {droopi }}}{Q_{\max i}} Q_{i}
\end{array}(i=1,2,3)\right.
$$

$\omega_{0}$ and $u_{0}$ are the droop starting point of frequency and voltage amplitude in this standalone microgrid. $\omega_{i}$ and $u_{i}$ represents the output frequency and voltage amplitude of DGi.
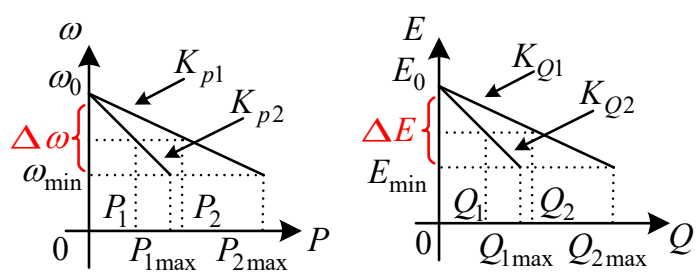

Fig. 3 Design of droop curve.

\section{Simulation Results AND Discussion}

In order to meet the high-penetration operation requirements of renewable energy, let wind power actively participate in system frequency adjustment and voltage support. Adaptive microgrid system with DFIG-based wind power and BESS has great application prospects. To realize the power sharing between DFIGs and BESS, an artificial droop curve is established. As shown in Fig. 3, the BESS and DFIG use the same droop starting point to realize the unified distribution of power flow.

In order to verify the effectiveness of the proposed control strategy, comprehensive simulation analysis under MATLAB/Simulink environment of the standalone microgrid including two DFIG and one BESS have been conducted. The main parameters of microgrid system are shown in Table I and Table II. Table I shows the parameters of DFIG and Table II shows the parameters of BESS and microgrid.

Two different situations are investigated. The first deals with fixed load, while the second uses a step load increase operation. Simulation results under different situation are discussed in the following part.

TABLE I

PARAMETERS OF DFIG

\begin{tabular}{lll}
\hline \multicolumn{1}{c}{ Parameter } & Symbol & Value \\
\hline \hline Rated Voltage & $U_{S}$ & $380 \mathrm{~V}$ \\
Rated Power & $P_{S}$ & $5 \mathrm{e} 3 \mathrm{KW}$ \\
Frequency & $f_{S}$ & $50 \mathrm{~Hz}$ \\
Poles of Pairs & $n_{p}$ & 2 \\
DC-link Voltage & $V_{d c 1}$ & $650 \mathrm{~V}$ \\
Switch Frequency & $f_{S w}$ & $8 \mathrm{e} 3 \mathrm{~Hz}$ \\
Stator Resistance & $R_{S}$ & $1.37 \Omega$ \\
Rotor Resistance & $R_{r}$ & $1.653 \Omega$ \\
Sampling Periods & $T_{S}$ & $5 \mathrm{e}-6 \mathrm{~S}$ \\
Inner Loop Gain & $K_{p i n}$ & 0.5 \\
Inner Loop Integral & $K_{i i n}$ & 10 \\
Mutual inductance & $L_{m}$ & $0.16 \mathrm{H}$ \\
$f / P$ droop & $K_{p f}$ & $1 \mathrm{e}-3$ \\
$V / Q$ droop & $K_{Q v}$ & 0.02 \\
\hline
\end{tabular}

TABLE II

PARAMETERS OF BESS AND MICROGRID

\begin{tabular}{llll}
\hline \multicolumn{2}{c}{ Parameter } & Symbol & Value \\
\hline \hline DC link voltage & $U_{d c}$ & $700 \mathrm{~V}$ \\
PWM switching frequency & $f_{s}$ & $6 \mathrm{e} 3 \mathrm{~Hz}$ \\
Power & Proportional gains & $K_{p v}$ & 0.05 \\
Controller & Integral gains & $K_{i v}$ & 390 \\
Current & Proportional gains & $K_{p c}$ & 10.5 \\
Controller & Integral gains & $K_{i c}$ & $16 \mathrm{e} 3$ \\
& Proportional gains & $K_{p p l l}$ & 0.0191 \\
PLL & Integral gains & $K_{i p l l}$ & 3 \\
& $f / P$ loop & $K_{f P}$ & $1 \mathrm{e}-3$ \\
Droop & $V / Q$ loop & $K_{V Q}$ & 0.02 \\
Controller & & $L_{f}$ & $0.1 \mathrm{H}$ \\
Equivalent & & $R_{f}$ & $0.23 \Omega$ \\
Impedance & & &
\end{tabular}

A. Voltage-Source Steady Operation of Microgrid 


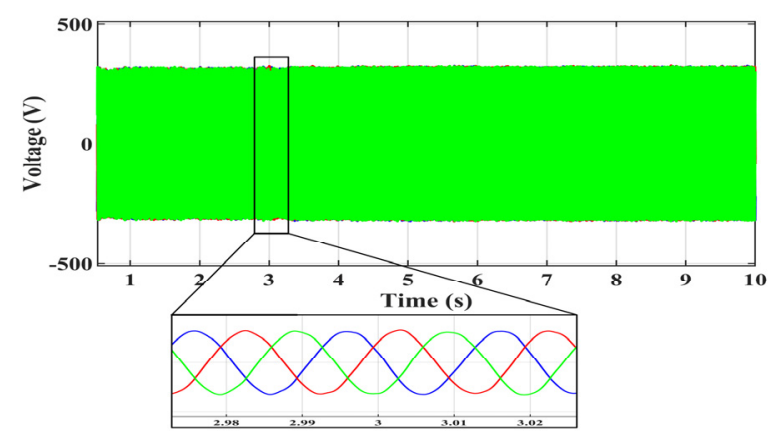

(a)

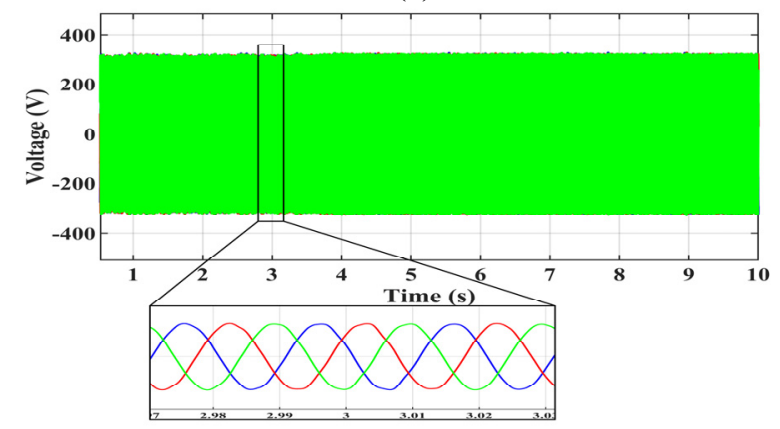

(b)

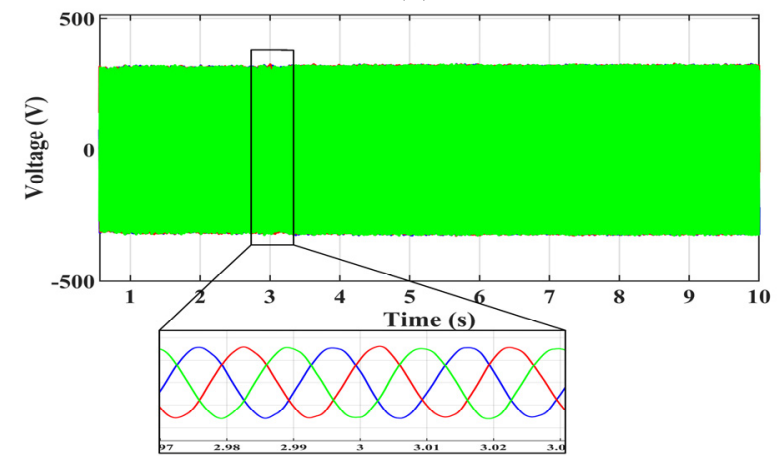

(c)

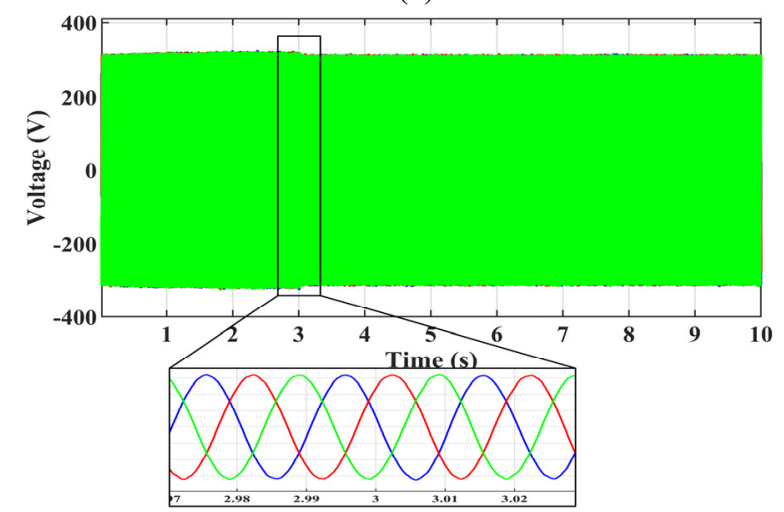

(d)

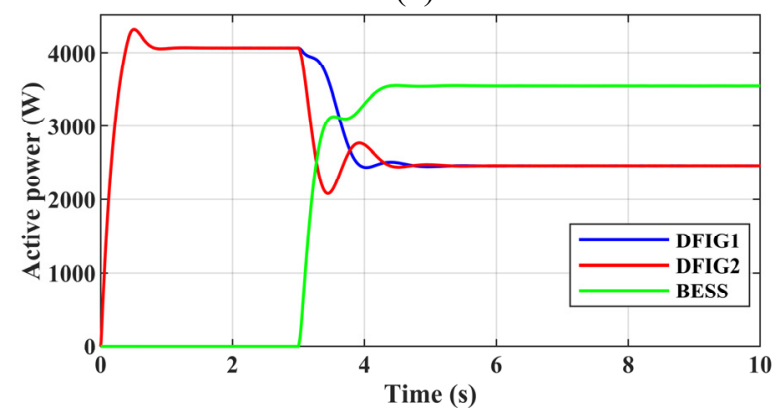

(e)

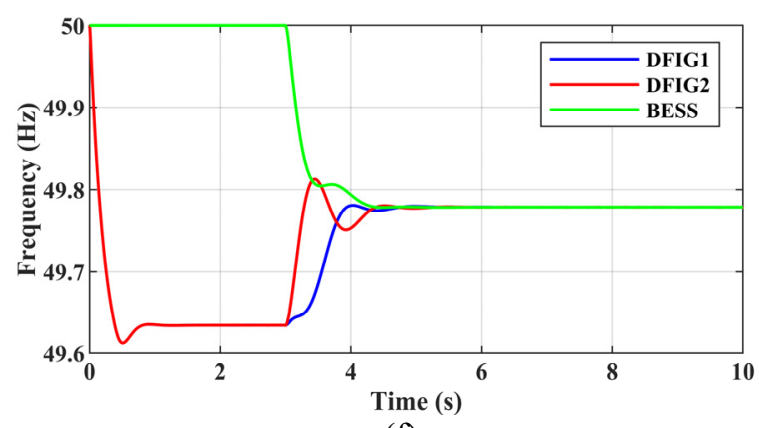

(f)

Fig. 4 System response of the microgrid under fixed load operation. (a) Output voltage waveforms of DFIG1. (b) Output voltage waveforms of DFIG2. (c) Output voltage waveforms of BESS. (d) Output voltage waveforms of PCC. (e) Active power. (f) Frequency.

Fig. 4 shows the system response of the standalone microgrid when adopting the proposed control methods above. As can be seen, the DFIG1 and DFIG2 both output power of $4000 \mathrm{~W}$ at the beginning when the BESS is not connected to the system. When the DFIGs and BESS system have been able to enter steady operation, connecting these two systems at $\mathrm{t}=3 \mathrm{~s}$. The output voltage of each distributed generation remains stable (see Fig. 4(a), (b), (c) and (d)). Due to the droop control loop, when two DFIGs and a BESS are operating in parallel, the power flow is divided automatically. As can be seen in Fig. 4(e), the power flow distribution conforms to the design of the droop curve.

B. Performance Under the Conditions of Step Load Increase of Microgrid

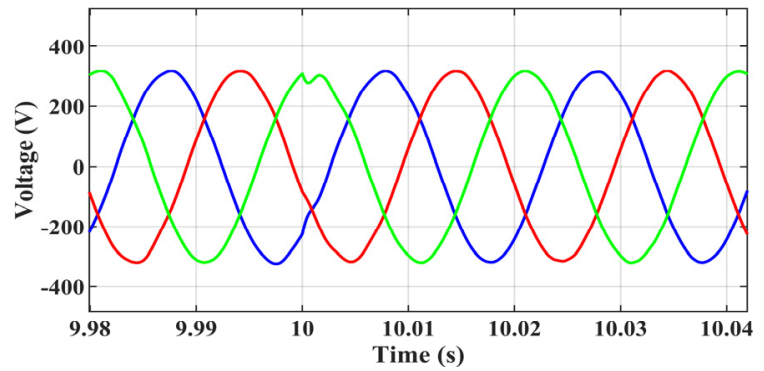

(a)

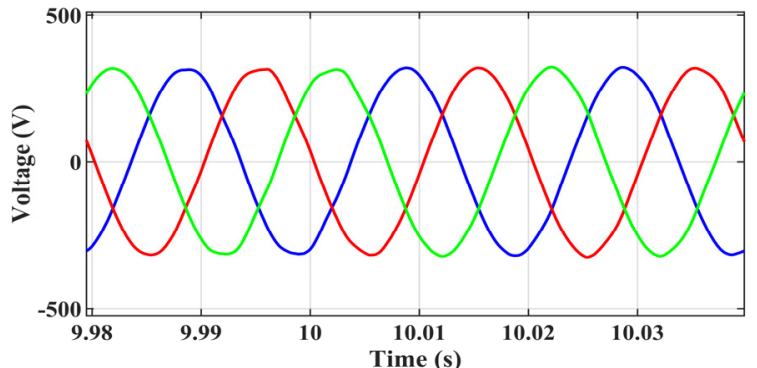

(b)

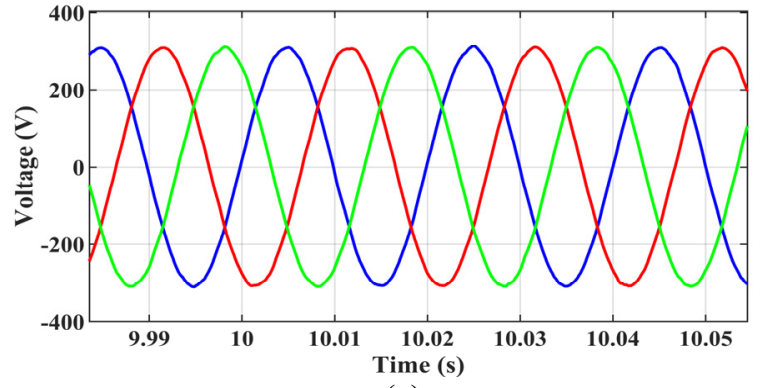

(c) 


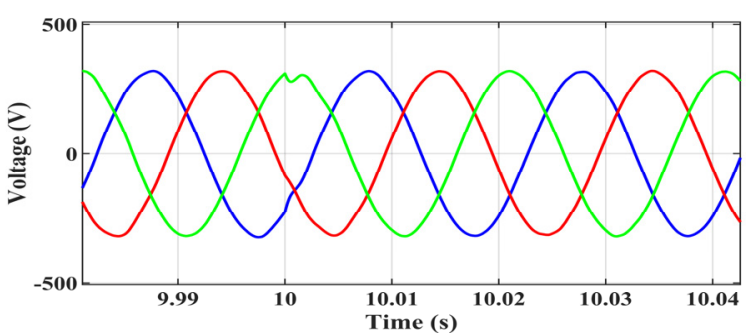

(d)

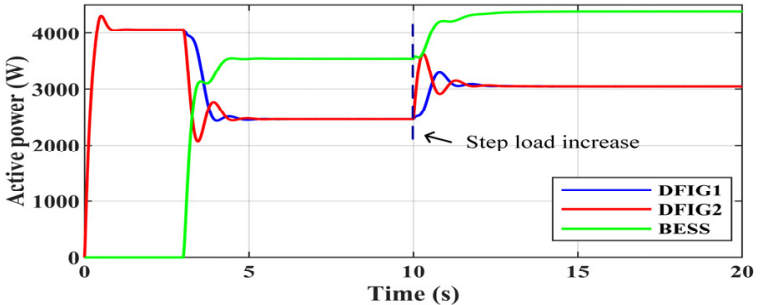

(e)

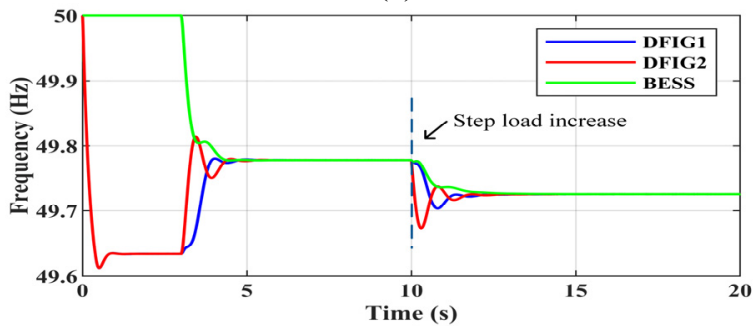

(f)

Fig. 5 System response of the microgrids under step load increase operation. (a) Output voltage waveforms of DFIG1. (b) Output voltage waveforms of DFIG2. (c) Output voltage waveforms of BESS. (d) Output voltage waveforms of PCC. (e) Active power. (f) Frequency.

Fig. 5 shows the dynamic performance of the standalone microgrid under step load increase of $2000 \mathrm{~W}$ at $\mathrm{t}=10 \mathrm{~s}$. It can be observed from Fig. 5 that the DFIG based sources are capable of participating in the regulation of microgrid frequency as autonomous voltage sources. When the load increases, the system frequency decreases and the DFIG systems adaptively increase the active power according to the dynamic droop control. Therefore, the control objectives of voltage-source control of DFIG have been achieved.

C. Comparison of Voltage-Source Control and Conventional Control Scheme of DFIG in Microgrid

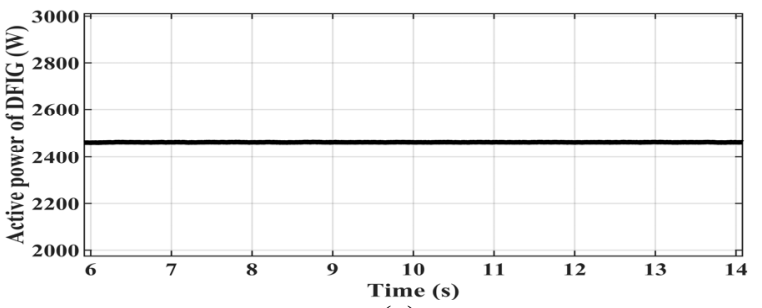

(a)

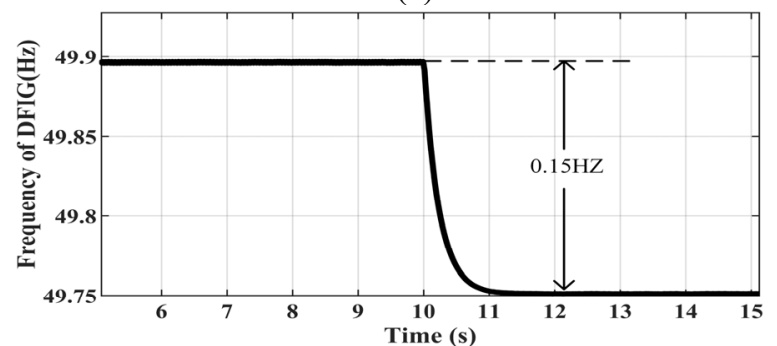

(b)

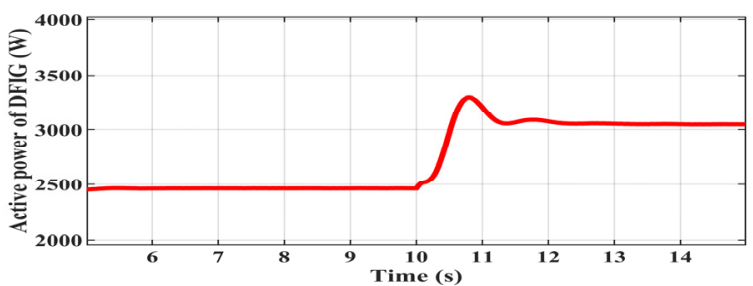

(c)

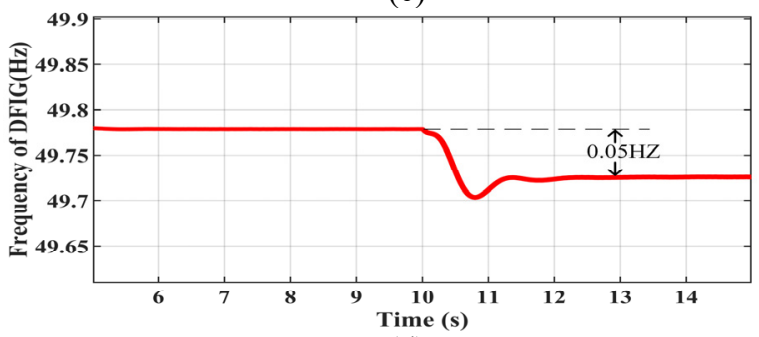

(d)

Fig. 6 System frequency and output voltage of the DFIG with different control strategy under step load increase operation (a) Active power of DFIG with traditional control strategy. (b) System frequency of DFIG with traditional control strategy. (c) Active power of DFIG with voltage source control strategy. (d) System frequency of DFIG with voltage source control strategy.

Fig. 6 shows the different performance between the traditional control strategies with the PLL and voltage source control strategy of DFIG. When the load increases at $\mathrm{t}=10 \mathrm{~s}$, the system frequency drops a lot with traditional control strategy compared with voltage source control of DFIG. It can be observed that the frequency regulation capability of DFIG-based voltage source microgrid is stronger than PLL control strategies which depend on the strong grid. Also, the extra load can be transferred to the BESS unit through the droop control. It can be observed from Fig. 6 that the voltage source control strategy allows wind power based microgrids to participate in system frequency regulation actively. Please note that this is significantly important in operation of DFIG based microgrid when the penetration rate of wind power is high.

\section{CONCLUSION}

This paper introduces the voltage source control strategy into the DFIG rotor side control to establish a power generation unit with the characteristic of DFIG voltage source output, which provides a certain basis for wind power to participate in system power and frequency modulation. Due to the control flexibility and rapid response of BESS, equipped with an appropriate amount of energy storage, and in coordination with wind power's own frequency regulation ability, can improve the economy of the system and enhance the stability of grid.

\section{REFERENCE}

[1] JA. Thakallapelli, S. Kamalasadan, K. M. Muttaqi and M. T. Hagh, "A Synchronization Control Technique for Soft Connection of Doubly Fed Induction Generator Based Wind Turbines to the Power Grids," IEEE Transactions on Industry Applications, vol. 55, no. 5, pp. 52775288, Sept.-Oct. 2019.

[2] A.G. Abo-Khalil, "Impacts of Wind Farms on Power System Stability," Rijeka, Croatia: In Tech, 2013.

[3] A. G. Abo-Khalil, et al. "Dynamic modeling of wind turbines based on estimated wind speed under turbulent conditions." Energies, vol. 12, no. 10, p. 1907, May 2019. 
[4] A. G. Abo-Khalil, "Synchronization of DFIG output voltage to utility grid in wind power system." Renew. Energy, vol. 44, pp. 193-198, Aug. 2012.

[5] J. Hu, Y. He, L. Xu and B. W. Williams, "Improved Control of DFIG Systems During Network Unbalance Using PI-R Current Regulators," IEEE Transactions on Industrial Electronics, vol. 56, no. 2, pp. 439451, Feb. 2009

[6] G. Abad, M. Á. Rodríguez, G. Iwanski and J. Poza, "Direct Power Control of Doubly-Fed-Induction-Generator-Based Wind Turbines Under Unbalanced Grid Voltage," IEEE Transactions on Power Electronics, vol. 25, no. 2, pp. 442-452, Feb. 2010.

[7] D. Santos-Martin, J. L. Rodriguez-Amenedo and S. Arnalte, "Direct Power Control Applied to Doubly Fed Induction Generator Under Unbalanced Grid Voltage Conditions," IEEE Transactions on Power Electronics, vol. 23, no. 5, pp. 2328-2336, Sep. 2008.

[8] Bevrani H, Raisch J, "On virtual inertia application in power grid frequency control," Energy Procedia, vol.141, pp. 681-688, Dec. 2017.

[9] M. F. M. Arani and E. F. El-Saadany, "Implementing Virtual Inertia in DFIG-Based Wind Power Generation," IEEE Transactions on Power Systems, vol. 28, no. 2, pp. 1373-1384, May 2013.

[10] Chengming He, Hongtao Wang, Donghua Sun, et al. "Analysis on frequency control characteristics of variable speed wind turbines and coordinated frequency control strategy of wind farm," Automation of Electric Power Systems, 2013.37(9).1-6.

[11] J. M. Mauricio, A. Marano, A. Gomez-Exposito and J. L. Martinez Ramos, "Frequency Regulation Contribution Through Variable-Speed Wind Energy Conversion Systems," IEEE Transactions on Power Systems, vol. 24, no. 1, pp. 173-180, Feb. 2009.

[12] Zhang Z S, Sun Y Z, Lin J, et al. "Coordinated frequency regulation by doubly fed induction generator based wind power plants," IET Transactions on Renewable Power Generation, 2012, 6(1): 38-47.

[13] Vidyanandan K V, Nilanjan S, "Primary frequency regulation by deloaded wind turbines using variable droop," IEEE Transactions on Power Systems, 2013, 28(2): 837-846.

[14] Y. Tan, L. Meegahapola and K. M. Muttaqi, "A Suboptimal PowerPoint-Tracking-Based Primary Frequency Response Strategy for DFIGs in Hybrid Remote Area Power Supply Systems," IEEE Transactions on Energy Conversion, vol. 31, no. 1, pp. 93-105, March 2016

[15] Shukla, Rishabh Dev, and Ramesh Kumar Tripathi. "A novel voltage and frequency controller for standalone DFIG based Wind Energy Conversion System." Renewable and sustainable energy reviews, vol. 37, pp. 69-89, Sep. 2014.

[16] Pena, Ruben, et al. "Control strategy for a doubly-fed induction generator feeding an unbalanced grid or stand-alone load." Electric Power Systems Research, vol. 79, pp. 355-364. Feb. 2009.

[17] L. Guo, D. Wang, L. Diao and Z. Peng, "Direct voltage control of stand-alone DFIG under asymmetric loads based on non-singular terminal sliding mode control and improved extended state observer," IET Electric Power Applications, vol. 13, no. 7, pp. 958-968, Jul. 2019.

[18] L. Guo, D. Wang, Z. Peng and L. Diao, "Direct voltage regulation of a stand-alone DFIG system with non-linear loads based on an improved-extended state observer and SSM control," IET Renewable Power Generation, vol. 13, no. 11, pp. 1891-1901, Aug. 2019.

[19] Z. Zhao, P. Yang, Y. Wang, Z. Xu and J. M. Guerrero, "Dynamic characteristics analysis and stabilization of PV-based multiple microgrid clusters," IEEE Transactions on Smart Grid, vol. 10, no. 1, pp. 805-818, Jan. 2019.

[20] X. Zhao, J. Dong, C. Zhang and X. Meng, "Modeling and stability analysis of autonomous microgrid composed of inverters based on improved droop control," 2016 IEEE 8th International Power Electronics and Motion Control Conference (IPEMC-ECCE Asia), Hefei, 2016, pp. 1720-1724

[21] Z. Zhao, P. Yang, J. M. Guerrero, Z. Xu, and T. C. Green, "Multipletime-scales hierarchical frequency stability control strategy of medium-voltage isolated microgrid," IEEE Transactions on Power Electronics, 2016, 31(8): 5974-5991

\section{BIOGRAPHIES}

Hai Xiao received the B.E. degree in electrical engineering and automation from the Jiangsu University of Technology, Changzhou, China, in 2018. He is currently pursuing the master degree in electrical engineering from the Guangdong University of Technology, Guangzhou. His current research interests include wind power based microgrids, and distributed generation systems.

Zhuoli Zhao (S'15-M'18) received the B.S. degree and the Ph.D. degree from South China University of Technology, Guangzhou, China, in 2010 and 2017, respectively. From October 2014 to December 2015, he was a Joint Ph.D. Student (Sponsored Researcher) with the Control and Power Research Group, Department of Electrical and Electronic Engineering, Imperial College London, London, U.K. He was a Research Associate with the Smart Grid Research Laboratory, Electric Power Research Institute, China Southern Power Grid, Guangzhou, China, from 2017 to 2018. He is currently an Associate Professor with the School of Automation, Guangdong University of Technology, Guangzhou, China. His research interests include microgrid control and energy management, power electronic converters, smart grids, and distributed generation systems. He is an Active Reviewer for the IEEE Transactions on Power Electronics, the IEEE Transactions on Smart Grid, the IEEE Transactions on Sustainable Energy, the IEEE Transactions on Industrial Electronics, and the Applied Energy.

Keyu Zhou received the B.E. degree from Harbin University of Science and Technology, Harbin, China, in 2019. He is currently a Graduate student in Guangdong University of Technology, Guangzhou, China. His research interests include microgrids, smart grids, and distributed generation systems.

Juntao Guo received the B.E. degree from Guangdong University of Technology, Guangzhou, China, in 2019. He is currently working toward the master degree in electrical engineering with the School of Automation, Guangdong University of Technology, Guangzhou, China. His research interests include microgrid control and energy management.

Chun Sing Lai (S'11, M'19, SM'20) received the BEng (First Class Honours) in electrical and electronic engineering from Brunel University London, UK and DPhil in engineering science from the University of Oxford, UK in 2013 and 2019, respectively. Dr Lai is currently a Lecturer at Department of Electronic and Computer Engineering, Brunel University London, UK and also a Visiting Academic with the Department of Electrical Engineering, Guangdong University of Technology, China. From 2018 to 2020, he was an Engineering and Physical Sciences Research Council Research Fellow with the School of Civil Engineering, University of Leeds. He is Secretary of the IEEE Smart Cities Publications Committee and Acting EiC of IEEE Smart Cities Newsletters. He is the Publications Co-Chair for 2020 IEEE International Smart Cities Conference. Dr Lai is the Working Group Chair for IEEE P2814 Standard. His current research interests are in power system optimization and data analytics.

Loi Lei Lai (M'87, SM'92, F'07) received BSc (First Class Honours) in 1980, PhD in 1984 and DSc in 2005 from University of Aston, UK and City, University of London, UK, respectively, all in Electrical and Electronic Engineering. He is University Distinguished Professor at the Guangdong University of Technology, China. He was Pao Yue Kong Chair Professor, Zhejiang University, China; Director of Research and Development Centre, State Grid Energy Research Institute, China; Vice President for IEEE SMC Society; Professor \& Chair in Electrical Engineering at City, University of London; and a Fellow Committee Evaluator for IEEE IES. He was awarded IEEE PES UKRI Power Chapter Outstanding Engineer Award in 2000, IEEE PES Energy Development and Power Generation Committee Prize Paper in 2006 \& 2009, IEEE SMCS Most Active Technical Committee Award in 2016. He is a Fellow of IET. His current research areas are in smart cities and smart grid. 